\title{
The Relationship between Web enjoyment and student perceptions and learning using a Web based tutorial
}

\begin{abstract}
Web enjoyment has been regarded as a component of system experience. However, there has been little targeted research considering the role of web enjoyment alone in student learning using web-based systems. To address this gap, this study aims to examine the influence of web enjoyment on learning performance and perceptions by controlling system experience as a variable in the study. 74 students participated in the study, using a web-based tutorial covering subject matter in the area of 'Computation and Algorithms'. Their learning performance was assessed with a Pre-Test and a PostTest and their leaning perceptions were evaluated with a questionnaire. The results indicated that there are positive relationships between the levels of web enjoyment and perceived usefulness and non-linear navigation for users with similar, significant levels of system experience. The implications of these findings in relation to web-based learning are explored and ways in which the needs of students who report different levels of web enjoyment might be met are discussed.
\end{abstract}

\section{Introduction}

Web-based learning is widespread in educational settings. Its value lies in the capabilities of hypermedia, which permit significant flexibility in the delivery of nonlinear course material (Khalifa and Lam, 2002). Students are allowed to learn in their own way - to determine their own path through the material available (Barua, 2001) and to learn things at their own pace (Chen, 2002a). However, with this increase in flexibility and freedom for the individual come potential problems for some users. Users are forced to determine their own navigation strategies, and they will therefore differ in their perceptions and approaches to learning. In particular, some users who lack the skills of independent study may find this difficult and become confused (Last et al., 2001), so they may forget what they have already covered, and miss out important information (McDonald and Stevenson, 1998). This suggests that not all students will appreciate the flexibility and freedom offered by the web and that the individual differences of students are therefore important factors to be considered in the development of web-based learning systems. 
Research into individual differences in web-based learning use has highlighted a number of attributes where individuals may differ, which may affect the ways in which they learn from and interact with web-based learning systems. These include gender differences (e.g. Schumacher and Morahan-Martin, 2001), cognitive styles (e.g. Kim, 2001), and system experience (e.g. Holscher and Strube, 2000). Among these, low system experience has been found to be related to navigational difficulties (Beishuizen et al., 1994). Since users who enjoy using the web tend to have greater system experience than those who do not (Liaw, 2002), enjoyment of using the web may also have an influence on these findings. However, current research lacks a full understanding of how enjoyment of using the web is related to web-based learning. Few studies have considered examining web enjoyment amongst experienced web users. To address this gap, the study reported in this paper examines the influence of web enjoyment of users with a relatively high level of system experience on their learning performance and perception. It is hoped that by assessing individuals’ learning experiences a greater understanding of the role of web enjoyment and system experience in web-based learning can be reached, enabling the development of improved web-based learning systems.

This paper begins by building a theoretical framework to present the relationships between web enjoyment and the use of web-based learning. It then progresses to discuss the current empirical study, which examines how the different levels of web enjoyment influence the students' learning performance and perception in a web-based learning system. Finally, the findings of this study are discussed by comparing with those of previous work, illustrating implications for the design of web-based learning systems.

\section{Theoretical Framework}

Web-based learning can use hypermedia techniques to present course material in a nonlinear structure, allowing learners to control their learning pace and offering numerous types of navigation support (Chen and Macredie, 2002). These features make the web a useful learning technology, offering advantages over traditional didactic learning environments (Khalifa and Lam, 2002) and linear multimedia tutorials (Barua, 2001). In terms of non-linear structure, students are provided with freedom of navigation. Learners 
have the opportunity to select what information to access as well as how to sequence the information in a manner that is meaningful to them (Lawless and Brown, 1997). In this way, learners can construct individualised knowledge structures by cross-referencing the related topics in the subject domain. It has even been claimed that the flexibility the web offers in both structure and style may make it the "most effective technology system to date for individualizing instruction” (Jonassen, 1988, p.14).

With regard to learner control, students are given control over their learning strategy (Large, 1996). The Web relies on learner control to be effective, since it is the student who determines which nodes to visit. This differs from lectures, for example, which are tutor-driven (Khafifa and Lam, 2002). Three types of learner control can be provided by web-based learning: (a) pace control - enabling the student to select the pace of work; (b) sequence control - allowing the student to decide the order in which to tackle lesson components; and (c) content control - pertaining to the kind of material and to the depth at which the material should be studied (Jarvey and Cote, 1999).

Navigation support is a critical design issue in web-based learning systems (Bateman and Harvey, 1998; Rogers and Erickson, 1998). In respect of this issue, web environments provide multiple tools for learners to structure their navigation strategies, including advanced organizers (Shapiro, 1999), graphical overviews (de Jong and van der Hulst, 2002) and structural cues (Nilsson and Mayer, 2002; Hsu and Schwen, 2003).

These features enable the web to work as a rich learning environment. However, these same features can cause problems for some students. For example, some students may become disorientated or get lost in such learning environments (Nielsen, 2000). In particular, they have difficulty in knowing where they are within the website, where they have been, and where they can go to find the information that they need and how the pages are related (e.g., Chen and Ford, 1998, Last et al., 2001). In addition, Quintana (1996) found that while students gain the advantage of flexibility in time, pace, and distance with web-based instruction, many of them feel isolated, suffer from a lack of motivation, or lack of support, and find that the feedback provided is too limited, and consequently drop out of their courses. These studies provide evidence that not all students gain enjoyment from using web-based learning systems. 
Previous research has explained enjoyment in different ways. Barnett (1990), for example, defined enjoyment as physical, social, and cognitive spontaneity, manifest joy, and a sense of humour. This definition emphasises that enjoyment is concerned with the individual's perception of how much fun he or she is having when undertaking an activity. In addition to those dimensions captured in Barnett's stance, Atkinson and Kydd (1997) investigated the effect of playfulness on web usage. Their results indicated that enjoyment had a significant effect on the purposes of web use. Those with higher enjoyment tended to use the Web for entertainment. Enjoyment can also refer to the extent to which the activity of using a computer system is perceived to be personally enjoyable in its own right aside from the instrumental value of the technology (Davis et al., 1989). On the basis of this definition, Khong and Song (2003) explored the relationships between users' emotions and products of Computer Technology (CT). They found that the capabilities of CT, especially optimization, were contributing factors to enjoyment, and that enjoyment plays an important role in users' attitudes to CT. Users who had higher levels of enjoyment showed more positive attitudes to CT. Similar results were obtained by the study of Venkatesh (2000), which conducted an experiment to assess the effectiveness of a game-based training method. The results indicated that ease of use perceptions were influenced by the degree to which people perceived using the system to be personally enjoyable. These studies demonstrated that enjoyment significantly influences users’ perceptions to computing systems.

On the other hand, several studies have shown that high computer experience and other system experience have been linked to greater enjoyment of users. Torkzadeh and Van Dyke (2002) examined the change of users' Internet self-efficacy, in terms of belief in their own ability to succeed, before and after computer training, with the results of their study indicating that computer training significantly improved Internet self-efficacy. In other words, when the users transfer from low experience to high experience, their Internet self-efficacy increases. In addition, Venkatesh (2000) showed that the effect of enjoyment on ease of use became stronger as users gained more direct experience with the system. Similarly, Yi and Hwang (2003) found users to have more positive perceptions towards the web after using it for a period of time: when they had more experience, they had greater enjoyment. Other research also indicates that system 
experience positively correlates with attitude to the use of the systems and negatively correlates with anxiety (Smith, Caputi, Rawstorne, 2000; Durnell and Haag, 2002).

In such research, enjoyment has tended to be seen as a function of system experience. However, the role of enjoyment in isolation has received considerably less attention.

There is, therefore, a need to investigate the influence of enjoyment when system experience is controlled for, enabling the true influence of the enjoyment to be explored. The results of such a study might help to guide the development of web-based learning systems that achieve the instructional goal effectively. This paper presents such a study, which aims to examine the influence of enjoyment, especially focused on web enjoyment, on users' learning performance and perceptions of a web tutorial, amongst users with a significant level of system experience. This paper subsequently discusses how the role of web enjoyment can help to guide the development of systems to match relevant system attributes with the needs of users.

\section{Methodology Design}

In order to achieve the aim, an empirical study was conducted. This section gives an overview of the methodology used and design of the study, and provides details of research instruments, procedures and the approaches of doing data analyses.

\subsection{Research Instruments}

Research instruments work as a guide in order to make sure that the same information is obtained from different participants. The research instruments used in this study included a web-based tutorial to teach students subject matter in the area of 'Computation and Algorithms', Pre-Test and Post-Test activities to measure the students’ preliminary understanding and their learning performance, and two questionnaires to identify students’ personal backgrounds, and perceptions and attitudes toward the web-based tutorial. The following sub-sections introduce and explain these instruments. 


\subsubsection{Web-based Tutorial}

A web-based tutorial was created containing material from the 'Computation and Algorithms' module taught as part of undergraduate degrees at Brunel University, UK. The tutorial included about 60 pages and the content was divided into six sections representing distinct topics. Interface elements included: (a) a title bar located at the top of the screen showing the section name being viewed; (b) a control panel with the choices for menu, map, index, and the other available sections; and (c) the main body of the tutorial, providing referenced links and subject categories for selection. Figure 1 shows the screen design of this tutorial.

\{Figure 1 Here

The design of this tutorial was underpinned by considerations of non-linear interaction and learner control. The tutorial provided the students with rich links within the text, as well as a variety of navigation tools, including a map, an index, and a menu. In addition, each topic was further split into four subject categories, comprising: (a) overview; (b) pseudocode; (c) example; and (d) analysis. There were two types of overview, a general content overview and overviews for each specific topic. In this way, the students were given the freedom to decide their own learning paths and to choose their favourite navigation tools and preferred content presentation so that their perceptions of non-linear interaction, navigation support, and content presentation could be identified by examining their replies to items in the questionnaire.

\subsubsection{Questionnaires}

Two paper-based questionnaires were created. The first of these (Questionnaire 1) asked the participants for background information, such as age, gender, and nationality, as well as information regarding domain knowledge and web enjoyment. Students’ domain knowledge, system experience, and web enjoyment were identified using five-point Likert scales consisting of the following options: 'very much', 'quite a lot', 'neutral', 'not much', and 'not at all'. 
The second questionnaire (Questionnaire 2) asked the students to express their perceptions of the web tutorial. This included a number of questions separated into categories such as "subject content”, "functionality and usability” and "general perceptions”. This questionnaire, therefore, allowed for the analysis of a wide range of user perceptions of the tutorial across a number of topics relevant to web-based learning. This meant that features of the system relevant to learner control, non-linearity, and navigation features could be assessed, allowing for a deeper analysis of any problems encountered by the participants. Table 1 presents examples of the questions that were used to assess these features.

\section{\{Table 1 Here}

Of the 42 questions, 18 were positively phrased (e.g., "I found the suggested route through this tutorial helpful”) and 24 were negatively phrased (e.g., "I felt the structure of the tutorial was not clear”). In other words, the number of positively and negatively phrased questions was almost balanced, in an attempt to reduce bias in the questionnaire. All statements used a five-point Likert Scale consisting of: 'strongly agree’; ‘agree’; 'neutral'; 'disagree'; and 'strongly disagree'. Students were required to indicate agreement or disagreement with each statement by placing a check mark at the response alternative that most closely reflected their opinion.

\subsubsection{Pre-Test and Post-Test}

The Pre-Test and Post-Test were designed to assess the participants' level of knowledge of the subject domain both before and after using the web tutorial. Students were evaluated with a Pre-Test to examine students' levels of prior knowledge of the subject domain and with a Post-Test to assess their learning achievement. Each used 20 multiple-choice questions. Each question had four different answers associated with it and a “don't know” option, and the students could choose only one of them.

The questions were matched on the Pre-Test and Post-Test so that each question on the Pre-Test had a corresponding similar (but not the same) question on the Post-Test. 
Creating similar questions on the Post-Test was achieved by either changing the order (e.g., "What is the correct order for these terms from biggest to smallest?" re-written as "What is the correct order for these terms from smallest to biggest?”) or, where appropriate, by substituting different numbers into the questions (e.g., "The sum of $i=0$ to 4 , of $2^{i}$ is equal to:” re-written as “The sum of $i=0$ to 3 , of $2^{i}$ is equal to:”).

\subsection{Procedure}

The study was conducted at Brunel University’s Department of Information Systems and Computing and was carried out over a number of sessions during a three-week period. Each student took part in one session only. Each session contained a group of students each working individually. Prior to carrying out the study, the students were informed that they were each to be paid $£ 5$ for their participation and that the tutorial could help them to learn the material from the course. This procedure was to ensure that a big enough sample could be obtained.

The procedure for the experiment was as follows:

1. On entering the room, the students were asked to sit in front of a computer and read a printed sheet of paper detailing the instructions for the experiment (what they would be asked to do, and for how long).

2. Students were then handed the first questionnaire (Questionnaire 1) to complete.

3. After completing the questionnaire, the students were given the Pre-Test to complete. The students were given a maximum of 15 minutes to complete the Pre-Test.

4. On completion of the Pre-Test, the students were asked to use the web tutorial to aid them in the learning of the module. The students were allowed to use the web tutorial for a maximum of one hour.

5. After using the web tutorial, the students were given the Post-Test to complete. As with the Pre-Test, they were allowed a maximum of 15 minutes to complete this. 
6. Finally, after the Post-Test, the students were given another questionnaire (Questionnaire 2) to complete. On completion of the second questionnaire, the students were thanked and paid for their participation, and left.

\subsection{Data Analysis}

In this study, the independent variable was the students' level of web enjoyment, which was measured in Questionnaire 1. The dependent variables included learning performance and learning perceptions. The former was measured by a 'gain score', which was calculated as the Post-Test score minus the Pre-Test score. The latter was determined by the students' responses to the various questions about the tutorial from Questionnaire 2. All questionnaire responses, where appropriate, were scored as: (a) 5= strongly agree; (b) 4= agree; (c) 3= neutral; (d) 2= disagree; and (e) 1= strongly disagree. Because the independent and dependent variables were scored on numerical scales, Pearson correlations were carried out on all of the data. Differences between pre-test and post-test scores were tested with a paired samples $t$ test (Stephen and Hornby, 1997). A significance level of $\mathrm{p}<0.05$ was adopted for the study.

\section{Discussion of Results}

\subsection{Overview of the Results}

The participants consisted of 74 undergraduate students enrolled in a computer science course at Brunel University. There were 13 females and 61 males. 60 of them were in the age range 19 to 29, and 14 were aged between 30 and 40. According to the results of Questionnaire 1, participants had "very much” or “quite a lot” of experience of using computers and the Internet. As shown in Figure 2, the participants' levels of Web enjoyment were found to be almost evenly distributed (Mean $=3.58$; Standard Deviation $(S D)=0.757)$, though very few students said that they did not enjoy using the Web at all.

\{Figure 2 Here

All of the participants were taking the module "Computation and Algorithms". There was a significant increase in performance from pre-test to post-test $(\mathrm{t}(73)=-2.845$, 
$\mathrm{p}=.006$ ). As such, the use of the web tutorial seemed to have a positive effect on student learning and the students' understanding of the material could therefore be argued to have seen an overall improvement. Table 2 summarises the overall learning performance of the participants.

\section{\{Table 2 Here}

No significant relationships were found between the levels of students' Web enjoyment and students' learning performance as measured by the gain score. However, there were significant relationships between Web enjoyment and their perceptions of the web-based tutorial obtained from Questionnaire 2. In particular, among 14 closed statements related to usefulness, levels of understanding, and non-linear navigation, significance was found in eight statements (Table 3). This suggests that web enjoyment had a significant interaction with these three issues. These results will be discussed in the following three sections.

\{Table 3 Here

\subsection{Attitudes to Usefulness}

There appear to be statistically significant relationships between levels of web enjoyment and students' attitudes toward the use of the web-based learning system. The students who had higher levels of enjoyment considered the tutorial to be more valuable, as evidenced in their responses to the questions which concerned the coverage that the tutorial offered ( $\mathrm{r}=.257 ; \mathrm{p}=.029)$, the practical examples provided $(\mathrm{r}=-.505 ; \mathrm{p}=.000)$, and the type and scope of support provided in terms of navigation tools ( $\mathrm{r}=-.340 ; \mathrm{p}=.003$ ). The students who had lower levels of enjoyment saw the tutorial as being of less value and showed different response with respect to the aforementioned issues. Table 3 shows the mean score and SD for each scale item. These results suggest that the web-based learning system was perceived to be more useful by the students who had a more enjoyable experience, suggesting a relationship between enjoyment and perceived usefulness. 
The findings are consistent with those of the study by Yi and Hwang (2003), which found that enjoyment played an influential role in determining the perception of usefulness within the web-based context. They also support the findings of other studies that enjoyment is an important contributing factor to the users' attitudes (e.g., Khong and Song, 2003; Venkatesh, 2000; Venkatesh and Davis, 1996). However, these studies do not identify the needs and preferences of the students with low levels of web enjoyment. The present study reveals that giving more practical examples and offering fewer navigation tools are two potential ways in which the perceived usefulness may be improved for the students with low levels of web enjoyment. Therefore, there is a need to conduct further studies to investigate whether perceived usefulness can be improved by incorporating these two features into web-based learning systems.

\subsection{Levels of Understanding}

In analysing the students' responses to the tutorial, the results indicated that there were relationships between enjoyment and levels of understanding. The students who enjoyed the web more considered that it was easy to understand the content $(r=.305 ; \mathrm{p}=.009)$, and that their understanding of algorithms had been improved ( $r=.398 ; \mathrm{p}=.001)$ through the use of the tutorial. On the contrary, the students who enjoyed the web less displayed opposite opinions. The mean score and SD for each scale item are presented in Table 4. These results are in line with those of previous research (Chen, 2002b), which

highlighted that positive perceptions could enhance users' understanding; whilst negative attitudes hindered their understanding. The findings also echo the views of Fullerton (2000) and Ford and Chen (2001), which showed that users performed better with a system design matching their preferences, whilst their performance was reduced when the design did not match their preferences.

\{Table 5 Here\}

These results imply that students with low levels of web enjoyment need additional help. One solution is to provide a reading list and additional supporting material, with which the students can undertake further study to enhance their understanding. Human support 
is another way to give additional help (Vansickle, 2000), for example by having

additional lecture-based tutorials provided for them. Alternatively, instructors can create an email list that includes all the email addresses of the students taking the same module, so the students can discuss their problems and share their experience with their classmates by using this email list. This may also provide a way to gain encouragement from each other, which may increase their enjoyment. The purpose of these approaches is to incorporate a number of different teaching strategies to ensure that there is at least one effective strategy for each learner.

\subsection{Non-linear Navigation}

Students' enjoyment of using the web had a positive correlation with the positive statements related to non-linear navigation and had a strong negative correlation with the negative statements. In other words, those who enjoy the web were less likely to struggle with non-linear navigation. On the other hand, those who had less enjoyment using the web were not confident with web navigation and met more difficulties in nonlinear learning. In particular, the levels of students' enjoyment had interactions with their responses to the use of links presented in the web tutorial. The students who had higher levels of web enjoyment thought that links could help them to understand relationships between topics ( $\mathrm{r}=.321 ; \mathrm{p}=.006)$ and they liked the fact that they could choose the topics according to their own needs ( $\mathrm{r}=.304 ; \mathrm{p}=.009)$. Conversely, the students who had lower levels of enjoyment found it difficult to know which links corresponded to the information they wanted $(\mathrm{r}=-.268 ; \mathrm{p}=.023)$. The mean scores and SD for each scale item are presented in Table 5.

\section{\{Table 6 Here}

Web enjoyment, therefore, may be an important factor that needs to be considered in the design of web-based learning systems. To help the students who had lower levels of enjoyment to feel comfortable with non-linear navigation, one of the solutions is to use annotated links, which provide students with more information about the destination of a link prior to selection (Hohl et al., 1996). Annotations can take the form of text and icons or can be encoded by colours, different font sizes or typefaces. Among the different annotation techniques, history-based annotations can work as a means to help students to 
know whether a link has been visited or not and perquisite-based annotation can be applied to provide students with information on the background relevant to the concept being learned. These techniques can help students to choose appropriate links that can support their information needs. Other solutions include advisement treatment to provide recommendations on the sequence to follow through the material (Shin et al., 1994) and advanced organisers to provide the relationships among topics (Farrell and Moore, 2001).

\section{Concluding Remarks}

The study has examined the influence of web enjoyment on users with a relatively highlevel of system experience on learning performance and perception. The main conclusion that can be drawn from the study's results is that students who enjoy the web are more able to cope with non-linear navigation and have more positive perceptions of the usefulness of the web-based learning. As these results suggest, some students may need greater support and guidance from instructors, while others may be able to follow web-based tutorials relatively independently. Since students with different levels of web enjoyment showed different preferences to the features of the web tutorial, there is a need to be aware of what problems such students have when planning to use web-based tutorials in educational settings. Thus, instructors should not assume that web-based learning is suitable for every student. There remains the need for guidance to ensure that all students can meet their learning objectives and, as such, it is important to consider versatility in system design to allow for use by a variety of individuals, rather than a particular user group.

This study has shown the importance of understanding the role of web enjoyment in the development of web tutorials, but it was only a small-scale study. Further studies need to be undertaken with a larger sample to provide additional evidence. Future research should also focus more closely on examining the reasons behind, and the factors motivating, enjoyment of using web-based learning. In particular, it would be interesting to see whether some learners do not enjoy using the web-based learning because they are sensitive to ineffective design and can reflect more accurately the value of the material. The findings of such studies could be used to establish an integrated framework for the 
development of web-based learning programs that can accommodate the preferences of learners with different levels of enjoyment.

\section{Acknowledgements}

The authors are grateful for the support of the Engineering and Physical Sciences

Research Council (EPSRC: GR/R57737/01).

\section{References}

Atkinson, M., \& Kydd, C. (1997) Individual characteristics associated with World Wide Web use: An empirical study of playfulness and motivation. Database for Advances in Information Systems, 28, 53-62.

Barnett, L. A. (1990) Playfulness: Definition, Design, and Measurement. Play and Culture, 3, 319-336.

Barua, S (2001) An interactive multimedia system on "Computer Architecture, Organization, and Design”. IEEE Transactions on Education, 44, 41-46.

Bateman, W. E., \& Harvey, F. A. (1998) Hypermedia navigation: Where do we go from here? Paper presented at the Association for Educational Communications and Technology, St. Louis. February 1998.

Beishuizen, J, Stoutjesdijk, E, \& Van Putten, K. (1994) Studying textbooks: effects of learning styles, study task and instruction. Learning and Instruction 4, 151-174.

Chen, S. Y. and Ford, N. (1998) Modelling User Navigation Behaviours in a Hypermedia-Based Learning System: An Individual Differences Approach. International Journal of Knowledge Organization, 25, 67-78.

Chen, S.Y. (2002a) A cognitive model for non-linear learning in hypermedia programmes. British Journal of Educational Technology, 33, 449-460.

Chen, S. Y. (2002b) The Relationships between Individual Differences and the Quality of Learning Outcomes in Web-based Instruction. In Proceedings of the ICEB Second International Conference on Electronic Business, p. 345-351

Chen S.Y., \& Macredie R. D. (2002) Cognitive styles and hypermedia navigation: development of a learning model. Journal of the American Society for Information Science and Technology, 53, 3-15.

Davis, F.D., Bagozzi, R. P. \& Warshaw, P. R. (1989) User acceptance of computer technology: a comparison of two theoretical models. Management Science 35, 982-1003. 
Davis, F.D., Bagozzi, R.P., \& Warshaw, P.R., (1992) Extrinsic and intrinsic motivation to use computers in the workplace. Journal of Applied Social Psychology 22, 1111-1132.

de Jong, T. \& van der Hulst, A. (2002) The effects of graphical overviews on knowledge acquisition in hypermedia. Journal of Computer Assisted Learning, 18, 219-231.

Durnell, A. \& Haag, Z. (2002) Computer self efficacy, computer anxiety, attitudes towards the Internet and reported experience with the Internet, by gender, in an East European sample, Computers in Human Behavior, 18, 521-535.

Farrell, I. H. \& Moore, D. M. (2001) The effect of navigation tools on learners` achievement and attitude in a hypermedia environment. Journal of Educational Technology Systems, 29, 169-181.

Ford, N. \& Chen, S. Y. (2001) Matching/Mismatching Revisited: An Empirical Study of Learning and Teaching Styles. British Journal of Educational Technology, 32, 522.

Fullerton, K. (2000) The interactive effects of field dependence-independence and Internet document manipulation style on student achievement from computerbased Instruction. Ed. D Thesis. University of Pittsburgh.

Hohl, H., Böcker, H. \& Gunzenhäuser, R. (1996). Hypadapter: An adaptive hypertext system for exploratory learning and programming. User Modeling and user adapted Interaction, 6, 131-156.

Holscher, C., and Strube, G. (2000). Web search behavior of Internet experts and newbies. Computer Networks 33, 337-346.

Hsu, Y. \& Schwen, T. (2003) "The effects of structural cues from multiple metaphors on computer users' information search performance" International Journal of Human-Computer Studies, 58, 39-55.

Jarvey, D. \& Cote, D. (1999) The Development of an Instructional Simulation on the World Wide Web. Available online at: home.istar.ca/ dicote/projects/ paper.htm, (accessed February 2004).

Jonassen, D. H. (1988) Designing Structured Hypertext, and Structuring Access to Hypertext. Educational Technology, 28, 13-16.

Khalifa, M. \& Lam R. (2002) Web-based learning: Effects on learning process and outcome. IEEE Transactions on Education, 45, 350-356.

Khong, P. W. \& Song J. P. (2003) Exploring User's Emotional Relationships with IT Products: A Structural Equation Model. Proceedings of DPPI 03. p. 45-50.

Kim, K. (2001) Implications of User Characteristics in Information Seeking on the World Wide Web. International Journal of Human-Computer Interaction, 13, 323-340. 
Large, A. (1996) Hypertext instructional programs and learner control: a research review. Education for Information, 4, 95- 106.

Last, D. A., O'Donnell, A. M. \& Kelly, A. E. (2001) The Effects of Prior Knowledge and Goal Strength on the use of Hypermedia. Journal of Educational Multimedia and Hypermedia 10(1), 3-25.

Lawless, K. A. and Brown S. W. (1997) Multimedia Learning Environments: Issues of Learner Control and Navigation. Instructional Science, 25, 117-31.

Liaw, S. S. (2002) An Internet survey for perceptions of computers and the World Wide Web: relationship, prediction, and difference. Computers in Human Behavior, 18, 17-35.

McDonald, S., \& Stevenson, R. J. (1998). The effects of text structure and prior knowledge of the learner on navigation in hypertext. Human Factors, 40, 18 -27.

Nielsen, J. (2000) Designing Web Usability: The Practice of Simplicity, USA: New Rider Publishing.

Nilsson, R. M., \& Mayer, R. E. (2002) The effects of graphic organizers giving cues to the structure of a hypertext document on users' navigation strategies and performance. International Journal of Human-Computer Studies, 57, 1-26.

Quintana, Y. (1996) Evaluating the value and effectiveness of internet-based learning. Paper presented at the sixth annual conference of the Internet Society, Montreal, Canada. Available online at: www.isoc.org/inet96/proceedings/c1/c1_4.htm, (accessed June 2004).

Rogers P., \& Erickson, M. (1998) Layers of navigation: Hypermedia design for an illstructured domain. Paper presented at the annual meeting of the Association for Educational Communications and Technology, St. Louis.

Schumacher, P. and Morahan-Martin, J. (2001). Gender, Internet and computer attitudes and experiences. Computers in Human Behavior, 17, 95-110.

Shapiro, A. M. (1999) The relationship between prior knowledge and interactive overviews during hypermedia-aided learning. Journal of Educational Computing Research 20, 143-167.

Shin, C. E., Schallert, D. L., and Savenye, W. C. (1994) Effects of learner control, advisement, and prior knowledge on young students' learning in a hypertext environment. Educational Technology Research and Development, 42, 33-46.

Smith, B., Caputi, P., \& Rawstorne, P. (2000) Differentiating computer experience and attitudes toward computers: an empirical investigation. Computers in Human Behavior. 16, 59-81.

Stephen, P. \& Hornby, S. (1997) Simple Statistics for Library and Information Professionals. London: Library Association. 
Torkzadeh, G., \& Van Dyke, T. P. (2002) Effects of training on Internet self-efficacy and computer user attitudes. Computers in Human Behavior, 18, 479-494.

Vansickle, S. L. (2000) Tenth graders' search knowledge and use of the World Wide Web. Ph.D. thesis. Georgia State University.

Venkatesh, V. (2000) Determinants of Perceived Ease of Use: Integration Control, Intrinsic Motivation, and Emotion into the Technology Acceptance Model,. Information Systems Research 11, 342-365.

Venkatesh, V. \& Davis, F. D. (1996) A Model of the Antecedents of Perceived Ease of Use: Development and Test. Decision Sciences, 27, 451-481.

Yi, M.Y. \& Hwang, Y. (2003). Predicting the use of web-based information systems, self-efficacy, enjoyment, learning goal orientation, and the technology acceptance model. International Journal of Human-Computer Studies, 59, 431449. 
Figure 1: Screen Design of the web tutorial

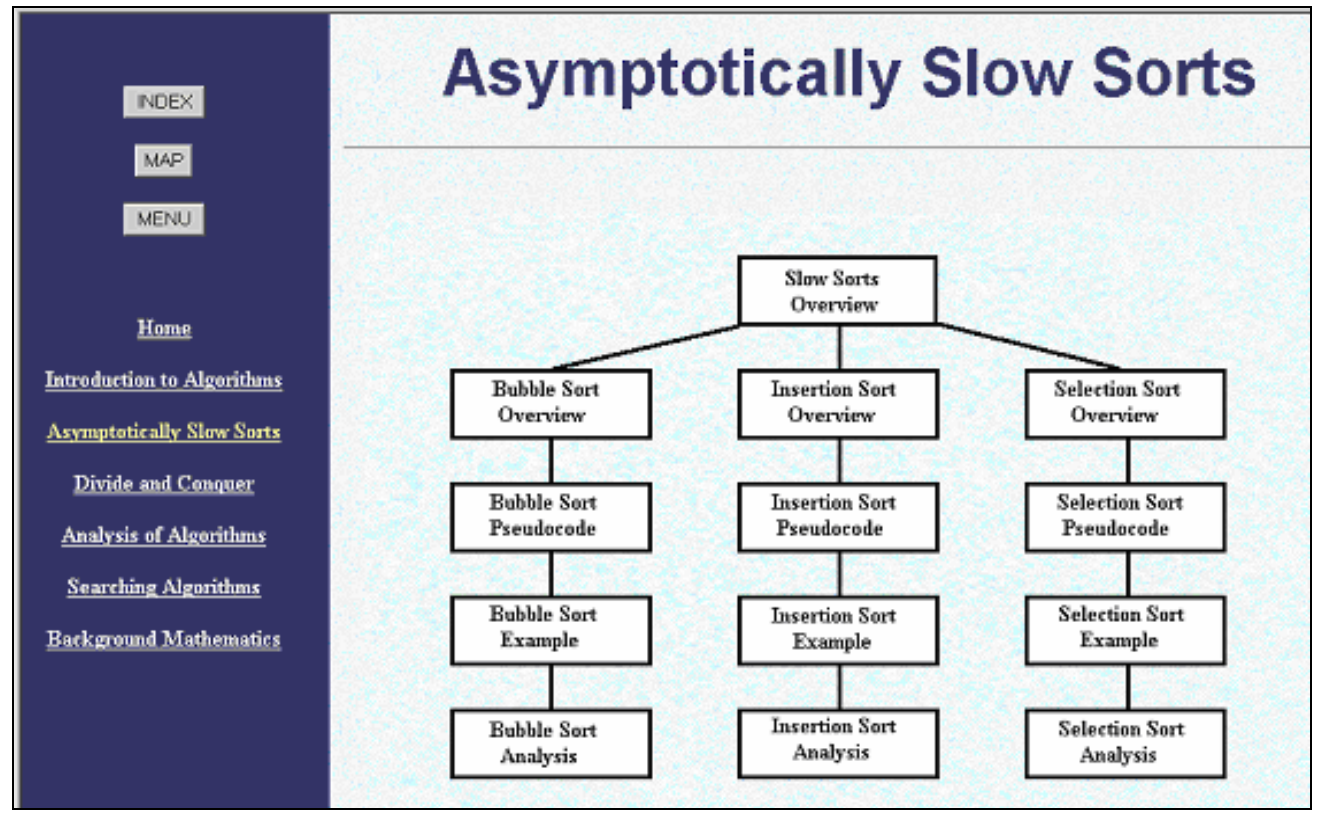

Figure 2: The Distribution of the Levels of Web Enjoyment

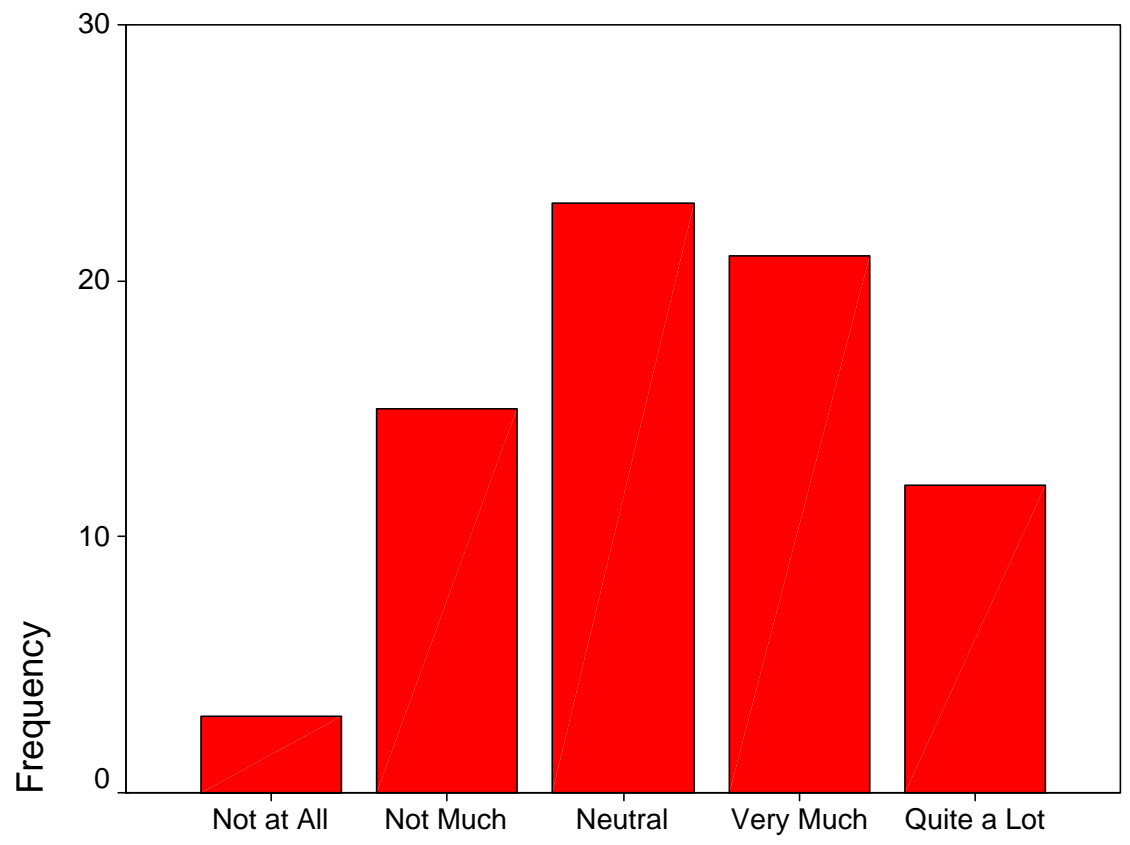

Levels of Web Enjoyment 


\begin{tabular}{|l|l|}
\hline Learner Control & $\begin{array}{l}\text { - I liked the fact that I can choose topics according to my } \\
\text { own needs. }\end{array}$ \\
& $\begin{array}{l}\text { I liked the fact that this tutorial allowed me to work at my } \\
\text { own pace. }\end{array}$ \\
\hline Non-linearity & $\begin{array}{l}\text { I got confused because the same page was available through } \\
\text { different links or buttons. }\end{array}$ \\
\hline Navigation & $\begin{array}{l}\text { I like the fact that this tutorial allowed me to learn topics in } \\
\text { any order. }\end{array}$ \\
\hline & $\begin{array}{l}\text { The tutorial contained too many navigation tools. } \\
\text { - } \begin{array}{l}\text { Links could help me to understand relationships between } \\
\text { topics. }\end{array}\end{array}$ \\
\hline
\end{tabular}

Table 1: Example Questions from Questionnaire 2

\begin{tabular}{|l|r|r|r|r|}
\hline & Minimum & Maximum & \multicolumn{1}{c|}{ Mean } & \multicolumn{1}{l|}{ SD } \\
\hline Score of Pre-test & 2.00 & 18.00 & 8.43 & 3.62 \\
\hline Score of Post-test & 1.00 & 18.00 & 9.41 & 3.87 \\
\hline Gain Score & -6.00 & 6.00 & .97 & 2.94 \\
\hline
\end{tabular}

Table 2: Overall Learning Performance

\begin{tabular}{|c|c|c|}
\hline & Significant & Non-significant \\
\hline $\begin{array}{l}\text { Attitudes to } \\
\text { Usefulness }\end{array}$ & $\begin{array}{l}\text { - Tutorial covers the module } \\
\text { very well. } \\
\text { - Examples in the tutorial } \\
\text { were not practical. } \\
\text { - The tutorial contained too } \\
\text { many navigation tools. }\end{array}$ & $\begin{array}{l}\text { I felt the structure of the } \\
\text { tutorial was not clear. } \\
\text { - I found the content of the } \\
\text { tutorial too detailed. } \\
\text { - It is hard to find a route for a } \\
\text { specific topic in this tutorial. }\end{array}$ \\
\hline $\begin{array}{l}\text { Levels of } \\
\text { Understanding }\end{array}$ & $\begin{array}{l}\text { - It is easy to understand the } \\
\text { content. } \\
\text { - Understanding of } \\
\text { algorithms has been } \\
\text { improved. }\end{array}$ & $\begin{array}{l}\text { My understanding of } \\
\text { algorithms has been } \\
\text { increased by visiting } \\
\text { different types of subject } \\
\text { categories. }\end{array}$ \\
\hline $\begin{array}{l}\text { Non-linear } \\
\text { Navigation }\end{array}$ & $\begin{array}{l}\text { Links could help me } \\
\text { understand relationships } \\
\text { between topics. } \\
\text { I could choose topics } \\
\text { according to my own } \\
\text { needs. } \\
\text { - It was difficult to know } \\
\text { which links corresponded } \\
\text { to information they wanted. }\end{array}$ & $\begin{array}{l}\text { I got confused because the } \\
\text { same page was available } \\
\text { through different links or } \\
\text { buttons. } \\
\text { - I like the fact that this tutorial } \\
\text { allowed me to learn topics in } \\
\text { any order. }\end{array}$ \\
\hline
\end{tabular}

Table 3: Significant and Non-significant statements 


\begin{tabular}{|c|c|c|c|c|c|c|}
\hline \multirow{2}{*}{\multicolumn{2}{|c|}{$\begin{array}{l}\text { Statements of the } \\
\text { Questionnaire }\end{array}$}} & \multicolumn{5}{|c|}{ Enjoyment in Using the Web } \\
\hline & & Not at All & Not Much & Neutral & Quite a Lot & Very Much \\
\hline \multirow{2}{*}{$\begin{array}{l}\text { Tutorial covers the } \\
\text { module very well. }\end{array}$} & Mean & 2.12 & 2.61 & 3.11 & 3.67 & 4.22 \\
\hline & SD & .299 & .811 & .511 & .913 & .801 \\
\hline \multirow{2}{*}{$\begin{array}{l}\text { Examples in the tutorial } \\
\text { were not practical. }\end{array}$} & Mean & 4.11 & 3.79 & 3.38 & 2.95 & 2.40 \\
\hline & SD & .155 & .811 & .566 & .040 & .153 \\
\hline \multirow{2}{*}{$\begin{array}{l}\text { The tutorial contained too } \\
\text { many navigation tools. }\end{array}$} & Mean & 4.21 & 3.78 & 3.22 & 2.78 & 2.23 \\
\hline & SD & .410 & .126 & .632 & .601 & .216 \\
\hline
\end{tabular}

Table 4: Attitudes to Usefulness

\begin{tabular}{|c|c|c|c|c|c|c|}
\hline \multirow{2}{*}{\multicolumn{2}{|c|}{$\begin{array}{l}\text { Statements of the } \\
\text { Questionnaire }\end{array}$}} & \multicolumn{5}{|c|}{ Enjoyment in Using the Web } \\
\hline & & Not at All & Not Much & Neutral & Quite a Lot & Very Much \\
\hline \multirow{2}{*}{$\begin{array}{l}\text { It is easy to understand } \\
\text { the content. }\end{array}$} & Mean & 2.15 & 2.64 & 3.11 & 3.67 & 4.22 \\
\hline & SD & .319 & .618 & .512 & .911 & .834 \\
\hline \multirow{2}{*}{$\begin{array}{l}\text { Understanding of } \\
\text { algorithms has been } \\
\text { improved. }\end{array}$} & Mean & 1.81 & 2.29 & 2.71 & 3.41 & 4.01 \\
\hline & SD & .518 & .921 & .705 & .125 & .316 \\
\hline
\end{tabular}

Table 5: Levels of Understanding

\begin{tabular}{|c|c|c|c|c|c|c|}
\hline \multirow{2}{*}{\multicolumn{2}{|c|}{$\begin{array}{l}\text { Statements of the } \\
\text { Questionnaire }\end{array}$}} & \multicolumn{5}{|c|}{ Enjoyment in Using the Web } \\
\hline & & Not at All & Not Much & Neutral & Quite a Lot & Very Much \\
\hline \multirow{3}{*}{$\begin{array}{l}\text { Links could help me } \\
\text { understand relationships } \\
\text { between topics. }\end{array}$} & Mean & 2.10 & 2.59 & 2.91 & 3.17 & 3.82 \\
\hline & SD & .449 & .888 & .539 & .983 & .874 \\
\hline & & & & & & \\
\hline \multirow{3}{*}{$\begin{array}{l}\text { I could choose topics } \\
\text { according to my own } \\
\text { needs. }\end{array}$} & Mean & 1.50 & 2.09 & 2.18 & 2.41 & 3.20 \\
\hline & SD & .548 & .944 & .751 & .152 & .398 \\
\hline & & & & & & \\
\hline \multirow{2}{*}{$\begin{array}{l}\text { It was difficult to know } \\
\text { which links corresponded to } \\
\text { information they wanted. }\end{array}$} & Mean & 4.01 & 3.69 & 3.30 & 3.03 & 2.00 \\
\hline & SD & .160 & .823 & .539 & .030 & .183 \\
\hline
\end{tabular}

Table 6: Non-linear Navigation 